\title{
Establishing Territorial Embeddedness within Retail TNC Expansion: The Contribution of Store Development Departments
}

\begin{abstract}
Establishing territorial embeddedness within host regions in international retail expansion is well-known to be important, although the processes underpinning its realisation are less explicit. This research analyses some "emerging practices" of international expansion planning by drawing on interviews across a sample of store development departments. The role of analysts within host regions in evaluating economic, institutional, cultural and social contexts and appraising the viability of market-entry methods and store formats is explored. The competitive and regulatory dynamism of regions means that behaviour which encourages greater embeddedness following market entry can be particularly helpful in strengthening the marketing and development strategies of international subsidiaries.
\end{abstract}

Keywords: embeddedness, knowledge, networks, retailing, TNC, store location analysis.

$\begin{array}{ll}\text { JEL classifications: } & \text { L2 (Firm Objectives, Organization, and Behaviour) } \\ & \text { L81 (Retail and Wholesale Trade/Warehousing) } \\ & \text { F23 (Multinational Firms/International Business) }\end{array}$

Final accepted version for publication in Regional Studies. June 2012

Steve Wood, The Surrey Business School, University of Surrey, Guildford, Surrey, GU2 7XH, UK. Email: sm.wood@ surrey.ac.uk (Corresponding author)

Jonathan Reynolds, Saïd Business School, University of Oxford, Park End Street, Oxford, OX1 1HP, UK. Email: jonathan.reynolds@sbs.ox.ac.uk 


\section{INTRODUCTION}

The rise of retail TNCs over more than two decades has received increasing attention across the social sciences (COE and WRIGLEY, 2009). From a geographical perspective research emphasises 'the fluid and complex nonlinear networks of firms' involved in international expansion across different spatial scales and how, in turn, this can affect their ability to exercise power and influence (COE, 2004, pp. 1572). Despite both internal and external barriers to growth (HUTCHINSON et al., 2009), large retail TNCs bring with them formidable capabilities, including 'new formats and pricing structures, improved information management processes, new marketing and merchandising methods, and high levels of investment capital' (COE and HESS, 2005, pp.451). However, the process of retail internationalisation is considerably more demanding than simply locating a retailer's favoured store format overseas (DAWSON, 2007).

It is well-established that manufacturing firms and service businesses need to achieve 'embeddedness' within their host region (PHELPS et al., 2003; LOVE et al., 2010), a concept linked to harnessing localised culture, knowledge and innovation as well as to enhancing the depth and quality of relationships with local firms (whether partners or suppliers), customers and other organisations (GERTLER, 2004). Similarly, retail TNC store development must be adapted to, and embedded within, specific competitive, institutional, regulatory, and cultural retail contexts (DONALD, 2008; WRIGLEY et al., 2005). It is also critical that the retail firm becomes embedded within the wider supply chain/distribution-logistic systems of the host region ${ }^{\mathrm{i}}$ and country, while also leveraging the kinds of scale-related (often more standardised) efficiencies that are associated with internationally expanding operators (COE and HESS, 2005; WRIGLEY and LOWE, 2010). Such adaptation has implications for initial market entry, store format and 
location strategy, as well as for the realisation of subsequent expansion programmes and appropriate marketing communication.

Despite widespread interest in the need for embeddedness within new markets for retail firms, research has been largely theoretical in nature. The manner in which international store location decisions are researched, analysed and executed in practice has been underemphasised. This research paper starts to address this deficiency from a multidisciplinary perspective. It investigates the role and practices of the store development (SD) function of retailers (responsible, mainly within medium- to large-size retailers, for the assessment of the viability of market entry to new regions and countries, the devising of store network plans and appraisal of specific development opportunities). Such departments are a particularly appropriate unit of analysis given their central importance in national and regional expansion, which requires a close understanding of the characteristics of the host market. Location analysts also have a boundary spanning role through liaison with other departments of the retail firm including marketing, property and operations. They can further extend their influence throughout the corporate hierarchy to affect the decision-making of senior management (WOOD and REYNOLDS, 2012).

In this research, we therefore examine how the need to achieve embeddedness in host markets is practically realised at a strategic management level in both market entry and subsequent expansion activity. Our study seeks to further develop and practically ground the theory of territorial embeddedness in retail TNC expansion. However, our concentration on store development departments inevitably means that our analysis primarily focuses on the customer-facing elements of embeddedness - namely conceptualising appropriate market entry mechanisms, store format types and customer- 
focused propositions - rather than upon other, equally important, 'back-end' elements of embeddedness such as sourcing, logistics and supply networks.

The paper is organised as follows: first, we review the contribution of the research literature to our understanding of territorial embeddedness within retail TNC expansion. Second, we consider the methodological approach adopted in the research. Third, we explore the results of a series of interviews with individual managers and analysts within store development departments to deepen our understanding of the assessment process underpinning territorial embeddedness within host regions. We conclude with a summary of the findings and implications of our research.

\section{EMBEDDED STORE DEVELOPMENT IN RETAIL TNCS}

The international expansion of a retail store network involves considerable sunk cost (CLARK and WRIGLEY, 1997) and can entail significant reputational risk (LOWE and WRIGLEY, 2009). Many of the constituent challenges are richly geographical in nature and include the interaction between the portfolio's spatial incidence and the competitive and regulatory frameworks of the host region (POOLE et al., 2002; WOOD, 2001), as well as the execution of the chosen form of expansion in relation to its target market and the firm's cost model (LAULAJAINEN, 1987; WOOD, 2002). The consequences of inappropriate strategic adaptation to customers and to the wider competitive, institutional and regulatory environment can be particularly damaging. Conversely, BENITO (2005) notes that companies adapting their operations to national conditions (what he terms a 'multi-domestic strategy') experience reduced levels of divestment an important issue since although international market exit can be managed sensitively (PALMER and QUINN, 2007), it is almost always unwelcome and often destructive of value. 
Economic geographers have conceptualised international expansion through the lens of the embedded and networked nature of economic activity within host environments. Drawing on HESS' (2004) theoretical contribution relating to embeddedness, research addressing retail TNC expansion has emphasised the central requirement of achieving territorial embeddedness 'in markets and cultures of consumption, planning and property systems, and logistical and supply chain operations' (WRIGLEY et al., 2005, pp.438; see Figure 1). In the process, successful retail TNCs adapt their strategic behaviour as they absorb the economic, regulatory and social dynamics that exist within newly entered regions, but they may also be constrained by such factors. The task of sustaining both territorial embeddedness and a differentiated identity within the host market is challenging, particularly within retailing given the ease of emulation and appropriability by competitors (COE AND WRIGLEY, 2007).

[Take in Figure 1]

Achieving suitable forms of store development does not solely rely upon territorial embeddedness. Closely related to, and contributing to its success, is network embeddedness, given that a firm's ability to adapt to, and subsequently expand within, a host market is partly governed by its networked relationships with a wide array of other organisations, whether this is via intra-, inter- or extra- firm relations that may be either formal or informal (HESS, 2004). Within retailing such relationships can occur between (joint venture) partners, suppliers, competitors, special interest groups and customers and are important given their role in providing the firm with knowledge, technology, expertise, legitimacy, and resources that may ultimately give rise to forms of competitive advantage (TACCONELLI and WRIGLEY, 2009). These networked relationships may be imported from existing operations elsewhere or formed within the 
host market itself and may be vertical or horizontal in nature (COE et al., 2008). Such alliances may be crucial to the ultimate success of the venture - for example, COE and LEE (2006) note the close inter-relationship between the establishment of store and sourcing networks.

Furthermore, a retailer expanding into a new market naturally brings with it 'some of the social and cultural attributes that it has acquired in the process of its own evolution within the context of its home base' (WRIGLEY et al., 2005, pp.441). Societal embeddedness therefore denotes what HESS (2004, pp.176) refers to as the firm's 'genetic code', influencing its strategic preferences. Given the likely differences between a retailer's origin and destination region, awareness of the implications of its own engrained perceptions are necessary to ensure appropriate adaptation. At its worst, societal embeddedness can lead to 'locked in' forms of behaviour that are manifested in a lack of receptivity or appreciation of alternative development forms (cf. BOSCHMA, 2005).

The use of the term embeddedness within economic geography is not without its critics. ANDREW JONES (2008) recently argued that the expression's usefulness is limited due to its under-emphasis of the relational nature of power and agency, resulting in a limited conceptualisation of the spatial development of economic activity. Instead, he advocates a practice-based approach that emphasises the relational (JONES and MURPHY, 2010). Our research presented here is, we believe, consistent with such a practice focus. While we are using the language of embeddedness to frame our understanding of retailer adaptability, our study is essentially focused on retailers' practices and therefore also upon the relational nature of expanding retail networks and 
the inequalities of power that may arise at different spatial scales within (and between) firms and the wider socio-economic environment.

Given our particular focus on the realisation of appropriate store network development, the emphasis in this paper is inevitably skewed towards conceptualising and contributing to our understanding of territorial embeddedness (see Figure 1). As store networks extend across international boundaries, retail TNCs must ensure that they are highly responsive to local variations in 'preferences that define distinctive cultures of consumption', as well as being 'sensitive to the property markets and land-use planning systems of host countries' (TACCONELLI and WRIGLEY, 2009, pp.54). The process of realising territorial embeddedness therefore highlights the need for retailers to 'achieve legitimacy in all markets that they operate' (BIANCHI and OSTALE, 2006, pp.146; OKEAHALAM and WOOD, 2009).

While work within economic geography concerning service business TNC diffusion may sometimes be presented as as 'an inexorable industry expansion across space', we must acknowledge that in reality it is 'a highly variegated process' that presents 'significant management and coordination challenges and is variably resisted and contested in different markets by combinations of regulators, domestic firms, labour unions and other civil society actors' (COE et al., 2011, pp. 69). Similarly, retail TNC expansion has commonly been characterised as waves of expansion of 'modern' retail practices and formats that have dramatically changed the 'rules of the game' for traditional retail markets and channels (HUMPHREY, 2007; REARDON et al., 2007). Yet an especially significant decision for a retail TNC derives from determining the extent to which it should modify or simply reproduce its domestic format(s), ranging, sourcing and marketing strategies within the host market. Hence embeddedness is 
framed very much as a dynamic and relational 'sociospatial-temporal concept' (JONES, 2008; YEUNG, 2009). Understandably therefore, it is suggested that a capability to adapt should be a key 'part of the knowledge base of all retailers' (DAWSON, 2007, pp. 390). Correspondingly much research - often undertaken in Asia - has emphasised how "western" store formats (supermarkets and hypermarkets) are sometimes poorly suited to the cultural tastes, traditions and requirements of indigenous consumers (CHANEY and GAMBLE, 2008). Although incumbent retailers may not possess the technology and sophistication of incoming retail TNCs, they are likely to be more attuned to local markets and cultures and therefore possess 'specific resources and capabilities [that] provide the means for these retail firms to compete internationally' (BIANCHI, 2009, pp. 235).

In numerous instances, the market exit of a retail TNC has been a function of its weakly embedded presence within a new international market. Wal-Mart's experience in Germany that led to its divestiture in 2006 is largely attributed to a lack of understanding of the competitive discounting inherent in the German retail market, strongly entrenched supplier relationships, and the subsequent psychology of the customer - in turn undermining the universal application of an Every Day Low Price (EDLP) -oriented, more efficient, 'big box' (large store format) strategy ${ }^{\mathrm{ii}}$ (cf. CHRISTOPHERSON, 2007). Similarly the experience of UK food retailer Sainsbury's in Egypt was suggestive of a lack of in-depth understanding of that market. While the retailer implemented advanced systems and techniques, it failed to embed itself sensitively within the Egyptian milieu, prompting a negative reaction from consumers (EL-AMIR and BURT, 2008). 
Given the specificities of overseas markets, new retail entrants therefore need to assess the nature and degree of localisation that is required in each case. This process is complicated depending on how new or unique an array of factors are to the retailer. These can include the region's institutional context and business customs as well as the characteristics of related suppliers, competitors, customers and their geographies. WHITLEY (2001) identifies three types of institutional environment that relate to formal regulations, as well as 'softer' norms of doing business which can produce barriers and opportunities for expansion - thereby affecting the organisation of firms. This typology has been employed widely to conceptualise the international expansion of service businesses (e.g. FAULCONBRIDGE et al., 2012; OKEAHALAM and WOOD, 2009; WRIGLEY and CURRAH, 2003; WRIGLEY et al., 2005) and is used in this study when assessing the dataiii. The typology comprises: first, 'collaborative' environments where the state plays a co-ordinating role with the existence of institutions that link the fortunes of workers, firms and clients together and therefore firms seek to collaborate to build long-term investment (e.g. continental western Europe, Japan and South Korea); second, 'arm's length' environments, which see the state acting more as a regulator than co-ordinator, leading to firms operating independently and seeking to minimise the impact of institutions on their operations (e.g. USA). Finally, WHITLEY (2001, pp. 39) identifies 'particularistic' environments, such as China, that combine 'a weak and/or predatory state ...with weak collective intermediaries and norms governing economic transactions' (cited by WRIGLEY and CURRAH, 2003, pp. 223). Within such challenging business contexts, firms tend to be opportunistic in orientation with a focus on short term profits and little investment for the future, and with little employer-employee trust or co-operation. 
Clearly then, while the 'direct transfer of retail TNCs' strategic assets—formats, commodities, various retail practices and know-how (e.g. shelving and display, sales events, distribution practices) is an important and cost effective means to achieve scale economies' (AOYAMA 2007, pp. 473), it is rarely that simple. BURT and MAVROMMATIS (2006) suggest that appropriate expansion consequently requires research 'on a structural and consumer behavioural level' in the new region to determine whether replication would result in the same distinctive position enjoyed in the domestic environment. Understanding the nature and implications of local cultures of consumption is, therefore, a pre-requisite (JACKSON, 2004). This has led many retail TNCs to capitalise on the embedded knowledge of local retailers at the point of market entry by either acquiring local operators (who have such knowledge) or devising joint venture arrangements to encourage the integration of the retail scale and efficient operating practices of the TNC with the more sophisticated understanding of the market and its associated networks, consumer cultures and regulations that the local retailer enjoys (COE and LEE, 2006; PALMER et al., 2010). Recent examples of retailers working to "localise" their retail proposition in this manner include Tesco's repeated use of local partners to provide region-specific knowledge and credibility - for example in its entry into South Korea - and its flexing of formats to local tastes (COE and LEE, 2006). Such a strategy can allow the retail TNC to 'adopt the appropriate business styles and avoid problems with nationalistic feelings from host consumers' (BIANCHI, 2009, pp. 236). Meanwhile, the recent entry of Tesco into the USA followed an extensive but ultimately not altogether successful period of fieldwork to understand the local consumer and competition, which included the trialling and subsequent introduction of a small supermarket format located at accessible locations to capture convenience customers (LOWE and WRIGLEY, 2010). 
While our study, through its explicit focus on engagement with store development teams, is particularly helpful in allowing us to explore the 'real estate markets and land use' and 'consumer markets and cultures' identified in Figure 1, we must remember that territorial embeddedness relies perhaps as much upon realising appropriately embedded 'logistical and supply networks'. Leading transnational retailers are well-known operators of supra-regional sourcing networks for non-food and general merchandise that have their own evolving geographies (PICKLES and SMITH, 2011; IVARSSON and ALVSTAM, 2011; TOKATLI and KIZILGÜN, 2010). Such direct imports can be characterised as the 'trojan horses' that REARDON et al. (2007) identify which can understandably concern the governments of host regions, though as COE and HESS (2005, pp. 463) note in the case of South-East Asia, such a situation may change as: 'local sourcing may actually increase over time as the supply base develops and retailers therefore import fewer products'. By contrast, in the case of fresh food supply chains, there is likely to be a more pressing need to establish embeddedness within the host region, not least to enable the retail subsidiary to achieve scalable growth post-market entry. In such circumstances, retailers are known to build relations with local suppliers who take on local processing, packaging and labelling activities and form part of the retailer's evolving logistics systems, often encompassing centralised distribution centres, that have tended to prove so successful within their domestic markets (COE and HESS, 2005). Commonly this involves constructing a centralised base of a (few) preferred suppliers that adopt the (private) standards enforced by the retail TNC (HENSON and REARDON, 2005). Such conditions potentially offer the opportunity for complex evolving geographies of sourcing where embedded local supply chains may be leveraged by the retail TNCs to act as an 'export gateway' for local suppliers to the other markets in which the retailer operates (NORDÅ, 2008; WRIGLEY and LOWE, 2010). 
It is not just a focus on initial store and supply network market entry that must be the concern of the internationally expanding retailer. It is also important that the firm quickly develops a market position that can be defensible in the face of likely competitive responses by domestic retail chains seeking to counter the effects of the new entrant (COE and WRIGLEY, 2007). As DICKEN (2000) has noted, international expansion is not only concerned with 'placing the firm', but is equally focused on the 'firming of places' whereby retail TNCs also influence the place in which they expand into - not least in terms of the effects on local competition and the diffusion of new retail technologies, formats and practices (HUMPHREY, 2007; REARDON et al., 2007). Retail market entry may, in turn, also result in a 'changing regulatory stance of the governments in those countries' (COE and HESS, 2005, pp. 460), often due to lobbying by domestic firms (COE and WRIGLEY, 2007), as has been the case in Thailand. This may take the form of changing retail planning regulations, restrictions on inward investment or tighter competition policy for example (MUTEBI, 2007), requiring further adaptation by the internationalising retailer. In this way, 'transnational retailers are not simply institution takers; rather, they contribute actively to influencing institutional change in the host economies they enter' (DURAND and WRIGLEY, 2009, pp. 1551-2).

Realising appropriate territorial embeddedness for TNCs therefore involves operators becoming sophisticated in managing (different types of) knowledge and guiding emergent networks and associated corporate cultures (FAULCONBRIDGE, 2006; 2008; JONES, 2005). Over time it becomes important for the TNC to develop the strategic competency of management learning alongside an ability to exploit knowledge transfer from (and between) failed and successful ventures (JONSSON, 2008; PALMER, 2006). 
Equally, specifically in the case of the retail TNC, the challenge exists of retaining the hard-won 'back office' efficiencies of a retailer's operations (such as merchandising, IT systems and supply chain), while also offering a customer-facing retail store, experience, product offer and environment closely suited to the host market (CURRAH and WRIGLEY, 2004). This process of mutual transformation and adaptation sees retailers engage in 'continuous morphing' as they constantly reassess and develop their competencies and competitive advantage, in circumstances characterised by intense competition (LOWE and WRIGLEY, 2010).

Having analysed the multi-disciplinary research literature relating to embeddedness within store network development by retail TNCs, it is clear that there are areas of relative under-development. By this we mean that, although there is a broad appreciation of the importance of appropriate forms of market entry and expansion along with the penalties of failing to do so, there has been less thinking in relation to how this is practically realised within retail firms. What procedures do retailers undergo to ensure targeted and tailored market entry strategies? Who undertakes such analysis and how is it set within the broader network of intra-firm relations? How is territorial embeddedness maintained within host markets following the initial market entry? The evidence provided in this paper seeks to inform our understanding of how territorial embeddedness is practically negotiated within retail TNCs.

\section{METHODOLOGICAL APPROACH: CLOSE DIALOGUE WITH STORE DEVELOPMENT DEPARTMENTS}

This paper focuses upon the role of SD departments in retail expansion in practice. Such units (the organisational nomenclature varies ${ }^{\mathrm{iv}}$ ) are typically placed either within, or closely adjacent to, property or marketing departments, and are required to advise the 
business on strategic opportunities related to store portfolio entry, expansion and its management. Typically, within domestic markets, SD departments at medium and largesized retailers are required to devise a network plan outlining the idealised geographical coverage of the store portfolio and to request property departments (or external property consultants) to bring forward appropriate sites for development. SD analysts then appraise and estimate the likely sales returns from these sites, making recommendations to senior managers. Departments are then involved to varying extents in the process of post-opening assessment, analysis and adjustment, often in collaboration with other retail support functions (WOOD AND REYNOLDS, 2011b; see Table 1). In the context of international retail expansion, these departments are also commonly employed to evaluate overseas opportunities and devise appropriate market entry and expansion strategies.

[Take in Table 1]

The extent of research conducted by firms to support store and wider portfolio decisionmaking in practice has often been criticised for its lack of rigor and its emphasis on 'experience' or 'intuition'. In practice, medium and large retailers are known to employ an array of models and tools to assist in decision-making (REYNOLDS and WOOD, 2010). Commonly used analytical procedures in store network planning include multiple regression; cluster analysis; analogue comparison; and spatial interaction/gravity modelling (see BIRKIN et al., 2002 for a comprehensive review).

The data for this article is derived from a broader research project with three methodological components. An initial online survey of named store development/property managers from 102 individual retailers generated $43 \%$ of usable 
responses. While the survey is not the focus of this particular paper, it provided useful background for many of the issues and aided us in devising an appropriate interview protocol. The main data collection exercise comprised semi-structured interviews with approximately 30 analysts and managers responsible for store development across a range of retail and related consultancy firms (see Table 2). Our interview sample was mainly drawn from the survey respondents but also from the membership list of a relevant UK-based industry support body, the Society for Location Analysis. Over a two year period, the authors participated in the meetings of this organisation and, in doing so, became part of an extra-firm network dedicated to the study and discussion of best practice in the analytics supporting store development. This provided direct access to a wide range of relevant individuals but also led to useful word-of-mouth recommendations for subsequent interviews.

[Take in Table 2]

The provisional conclusions from the interviews were then discussed in the third and final stage of research: a focus group of 10 SD analysts, which sought to establish whether our findings fairly represented the complexity of the issues involved. None of the focus group participants had featured in the previous stage of the research. The discussion was conducted as part of an executive education residential development programme for store development planning. We aimed to explore individuals' understanding through informal group discussion and interaction: the session was not recorded, although written notes were taken.

While most medium to large-sized retailers operated a store development planning function of some form, sometimes these were not organised as wholly independent 
analytical departments, but were instead units, or even single individuals, situated within property or marketing departments. Consequently, some of our interview subjects had job titles relating to property management or, in some instances, operational management (as in the case of some smaller retailers). This was advantageous for us in providing a broader perspective upon the intra-firm context of embedded store development decision-making. However, to ensure comparability, the interview structure remained consistent: organised around themes related to retail store development and specific network planning issues before broadening out to consider the individual manager's wider role and its associated intra-firm context.

The data collection process was designed to ensure a representative sample of operators across different retail sectors and sizes, with differing degrees of international experience. Interestingly, respondents often had extensive experience not only at their current employer but also from a career history of domestic and international involvement in SD with a number of other retailers and consultancies. Interviews were conducted on the basis of confidentiality at both the company and individual level and were typically of between 45-90 minutes duration, at each firm's head or regional office. They were recorded, transcribed and then subject to coding and subsequent analysis in line with accepted qualitative research practice (BRYMAN and BELL, 2003). Our research approach sought to reproduce the kind of qualitative rigour commonly referred to as 'close dialogue' with relevant senior corporate actors (CLARK, 1998). Our analysis includes quotations designed to illustrate the perceptions, beliefs and experiences of the managers consulted. In common with much other qualitative research drawing on commercially sensitive information (e.g. LOWE and WRIGLEY, 2010; HUGHES 2012), the identity of individual respondents has been obscured, but the retail sector within which they are employed has been noted. 


\section{REALISING TERRITORIAL EMBEDDEDNESS IN RETAIL TNC EXPANSION}

Economic geographers adopting a relational perspective have emphasised that international expansion must be framed as a socialised and networked process, underlining the interconnectedness and interactions between employees, customers, firms and institutions in economic decision-making (BATHELT and GLÜCKLER, 2003; COE, 2004; FAULCONBRIDGE, 2010). Unsurprisingly therefore, the wider internationalisation literature has been criticised for its implicit assumption of 'atomistic decision procedures' given the wide range of intra-, inter- and extra- firm influences that expose the shortcomings of simple rational decision-making assumptions (GLÜCKLER, 2006, pp. 374). It is particularly instructive, therefore, to draw from these interviews some of the practical aspects accompanying the reality of territorial embeddedness.

[Take in Table 3]

Necessarily, we use the term "emerging practices" rather than a single "best practice" to describe the various stages of assessment and analysis that become apparent in firms' activities, since it becomes clear that even the largest and most experienced firms are 'learning by doing' and that there is no standardised or universal approach within the industry. While we identify separate stages of analysis, we are not suggesting there exists some mechanistic 'cookie-cutter' approach to international decision-making and strategic adjustment. Rather, the analysis below and the accompanying table attempt to retrospectively categorise what appears to occur within successful retail multinationals to facilitate appropriate embeddedness within overseas markets (see Table 3). Implicit within the timeline is a focus on detailed market analysis to inform strategic planning to 
allow informed reflection on performance and assess the implications for future strategic adjustment, as well as to develop (and be informed by) management learning and knowledge transfer from both failed and successful ventures.

\section{Pre Market Entry: Country Screening}

Our interviews suggested that the decision to embark upon initial international market search within specific countries tended to be made by senior management within the retail firm for a range of motivations - some of which arose from personal ambitions and preferences (cf. GLÜCKLER, 2006) - underlining the limitation that many conceptual models of international market selection have in their applicability to retail firms (ALEXANDER et al., 2007).

Given the challenges raised by information asymmetry in formulating a market entry strategy (DOHERTY, 1999), the pre-market entry phase was especially demanding and largely dictated the retailer's approach to embedding itself in the market. Our data confirmed a typical two-step approach to preliminary appraisals of countries: First, an initial pre-screening phase dominated by desk-based analysis (referred to by ALEXANDER and DOHERTY (2009) as 'market scanning'), which allowed the development of a refined list of targets, before a second, more in-depth analysis phase focused on the collection of primary data relating to potential regions and catchments for initial entry, along with the consideration of entry methods that might be employed.

Essentially, the scanning stage of international market analysis signalled a departure from the conventional day-to-day role of analysts within domestic markets that tended to centre on the idiosyncrasies of specific catchments within well-understood regions. Instead, the focus shifted to issues of macro-scale viability within a novel host 
environment. This tended to demand higher order analytic skills where more experienced analysts in the appraisal teams needed to make decisions on a partial evidence base. This saw a focus on population size and the political and regulatory stability of the region alongside interest in the absolute value and rate of change in the size, competition and structure of the retail market (see Table 3).

Even at this early stage, some preliminary consideration of entry method frequently occurred, given its importance in realising territorial embeddedness, as well as its consequences for network relations (whether through the use of particular partners or the implications for sourcing and supply chains). Indeed, as ALEXANDER and DOHERTY (2009) suggest, the apparent division between market selection and choice of entry method is not necessarily as distinct as some literature suggests. As one food retailer noted, analysis of the retail competition at the screening stage inevitably led to consideration of acquisition or joint venture opportunities, thereby underlining the linked and contingent nature of the different stages of the market entry process (cf. GLÜCKLER, 2006):

'...we have a vital role in terms of identifying what the market entry method perhaps should be [and also]... should we be going into a country at all?... What's the opportunity? So looking at market size, how strong are the existing players, are there any opportunities through acquisition? So, if there are existing players that are perhaps looking to get out of that country for one reason or another, would that work for us if we acquired them, or you know, going in as a joint venture, or should we be going in organically?' (Food Retailer).

We found that joint ventures were particularly attractive for food retailers considering market entry to what WHITLEY (2001) regards as 'particularistic' markets that were highly differentiated from institutional, cultural and regulatory environments with which western retailers were familiar. At the end of this largely office-based process, a preliminary report was typically sent to senior managers to provide top-level analysis of 
all of the countries under consideration. The report would seek to prioritise those markets where primary research into potential entry methods and particular regions would be merited, with a view to producing an idealised store network plan.

\section{Pre Market Entry: Entry Method and Potential Catchment Analysis}

As the opportunity for market entry and subsequent development became more serious, so the analysis conducted by SD departments became more rigorous. This demanded greater human and financial resources and often saw SD analysts deployed typically on a short-term basis from the domestic business to target countries to appraise consumer cultures, potential competitors and joint venture/acquisition partners, as well as opportunities for organic store growth within selected major catchments, at first hand.

A critical role for analysts in their overseas deployment was to determine an ideal store entry method and to quantify 'the size of the opportunity' - a major consideration given the opportunity cost of capital. At this stage, any joint venture partners or acquisition candidates were assessed more closely, most likely through desk research but also, if interest persisted, via incognito visits to stores to assess their store environment, product offers, locations and crucially the competitor set within the region of interest. Candidate retailers were generally considered if they were well placed currently within the market in terms of sustainable logistics and supply networks, store performance and possessed defensible store catchments but also demonstrated some capability for scaling up store development to establish market leading positions.

Central to the development of any strategic plan was an assessment of particular store formats and locations that would prove to be viable within the cultural and regulatory context of the host market: 
'[We would be] asked to do a strategy...of how many stores do we think we could build, what's the opportunity, where would we build them, what formats would we look at... Then also, they would expect some basic numbers as well. You know, they want to quantify, okay, if we put 100 "strategy locations" down, as an initial go, then what we think those strategy locations could take [in sales]' (Food Retailer).

However, the complexity of analysis achievable at this stage was often limited by an inability to employ complex modelling procedures given the lack of local data - by contrast with domestic store development planning, where decision-making is augmented by sophisticated sales forecasting models. Instead analysts employed relatively elementary assessment techniques, with an emphasis on 'experiencing' the host market via regional, market-based and specific site visits, alongside the interrogation of publicly available data relating to catchments, customers and competition. As one manager with experience of a particularly data-poor environment reflected:

\footnotetext{
'we don't have anywhere near as much data or knowledge usually... even getting accurate population data is very difficult, let alone expenditure data, competitor data. So I would say models are a lot more basic, so we would still try and develop some form of model... but it won't be like a complex gravity model. It might be a regression model. It might be...a simple set of analogues, using competitor data, if we can get it' (Food Retailer).
}

Within data poor (and often 'particularistic') environments, understanding the retail structure of potential host markets became a 'bottom-up' process. Nevertheless, SD analysts are often well-suited to such locations, familiar as they are with making sense of partial data. As one food retailer reflected:

'the basic fundamental of a site researcher's job is asking questions about data... It's then very transferable to a different country. It's tougher questions, not necessarily [with] clear-cut answers, worse data, more simplistic models, more gut-feel, more intuitive, but still similar kinds of questions and something 
that... an accountant-based business analyst might struggle to answer' (Food Retailer).

Such situations often demanded primary survey and observation work to articulate the emerging retail structure. One consultant reflecting on an Asian retail market entry commented:

'It makes us have to go right back to basics...the first thing we have to do is define where all the retail centres are in these places.... We've done it right across Asia-Pac now...In Korea, we've defined 3,000 retail centres in Seoul. Nobody else has done that' (Location Planning Consultancy).

Among our sample, it was atypical for such lengthy and detailed market analysis to be conducted. It was more common for a team of analysts to make an extended visit rather than posting executives for prolonged periods to the host region(s) at a pre-market entry stage. The length of fieldwork analysis was mainly (and somewhat logically) the degree of investment and sunk cost that was being contemplated., The more lengthy periods of in situ analysis were more common with food retailers rather than clothing retailers, given the relative nature of their investments. A physical analyst presence within the target country clearly permits a closer understanding of market dynamics, at least in principle, prior to any modelling or large scale data manipulation. As part of this process, SD analysts may have to quickly 'unlearn' assumptions that they may have built up within their domestic market in order to avoid a preordained understanding of what drives retail sales within the region and its related cultures of consumption. As one analyst now working in an under-developed 'arm's length' retail market in Australasia observed, the situation contrasted sharply with her domestic experience - underlining her own societal embeddedness:

'[It is] a whole new geography, a whole new kind of demographics of a country... what's affluent and what's value changes completely, country versus 
city, and all the competition is obviously totally different....and it's a totally different market, where your high street shops and your independents play a much more important role' (Food Retailer).

In the process, it was often recognised that the heterogeneity of regional retail markets within countries led to different format and marketing mix requirements. Importantly also, analysts remained conscious of how these requirements related to the competencies and capabilities of the expanding retailer (cf. CURRAH and WRIGLEY, 2004).

Our respondents often pointed to the benefit of having a dedicated team of SD analysts and associated property development managers based within a target country once a decision had been made to enter a new market to assist in reducing the length of time required to achieve significant scale by means of organic growth. Embedded analytical teams are closer to the institutional, regulatory, economic and cultural climate of the host region, which makes it easier to formulate appropriate entry and expansion plans. As one analyst commented in discussing entry to a high profile competitive market (classified by WHITLEY (2001) as ‘arm's length'), this physical proximity was an especially important variable in realising success and gaining first mover advantage over the indigenous competition:

'the idea was have the team on the ground, get the sites backed, get the approvals, get everything agreed at the Board, and then you would hit the ground running when you opened. So you're not opening one store and then you have to wait six months while another site comes in. You've got all these sites, you've got the processes set up, before you even start' (Food \& General Merchandise Retailer).

Given the likely imitative competitive responses by indigenous retail chains (COE and WRIGLEY 2007), this is especially important. For example, for food retailers with complex supply chain requirements, the exporting of retail talent to a target country at 
an early stage can be far more than that required just for SD planning and can encompass all aspects of the retail operation - something that was the case in this particular country. As pointed out by one analyst:

'you'll take the best of that domestic expertise - and export it, be that Operations, be that Finance, be that...Supply Chain, Site Research...Y You don't want to screw that up as well because it's big bucks, and getting it wrong is so expensive' (Food Retailer).

This underlines the extent to which store development and the "back office" aspects of the retail TNC, including sourcing, IT systems and supply chain cannot be convincingly divorced from each other in the market assessment process (cf. COE and LEE, 2006; SWOBODA et al., 2007).

Our interviews also suggested that in instances where market knowledge was scarce and/or there was a lack of confidence in developing a viable store network, it could be effective to develop the retailer's own network embeddedness. In such circumstances interview respondents acknowledged the benefits arising from combining the local knowledge of retail joint venture partners with that of an experienced global operator ${ }^{\mathrm{v}}$. As an analyst from one experienced global food retailer acknowledged, they would typically 'identify a good retailer, learn the local knowledge and the basics from that retailer, adding the [expanding operator's] know-how of how to grow a...great retail business, and you've got the best of both worlds'. This is a considerable challenge as it is known that joint ventures and acquisitions involve what BENITO (2005, pp. 239) regards as 'double layered acculturation' whereby new regional and corporate cultures both have to be addressed. In such instances the presence of a SD team sometimes smoothed inter-firm relations between the market entrant and the joint venture partner but could also provide a means of sharing practices between the two parties at an early 
stage, in order to identify any impediments to suitably embedded store networks and wider operations. As one food retailer with extensive experience of joint venture relationships acknowledged in the case of one market entry to a largely untapped yet rapidly emerging Asian market:

'we still had a team on the ground [throughout the market assessment process]. I think a lot of that is trying to understand the market, you know, at the point - both before market entry and once the strategic decision had been made...get processes set up working with the local partner, and try and educate them I guess to [our] way' (Food Retailer).

The additional benefits of liaising with a local partner "on the ground" included allowing SD teams to quickly establish a detailed understanding of the market dynamics of the region, as well as generating access to important contacts who could facilitate more rapid expansion - thereby aiding network embeddedness at an early stage of growth. This is especially important within 'particularistic' business environments where there is less clarity and adherence to western approaches to business relations and regulation:

'a local partner... may have connections that we can't possibly get... They may have links within Government. They may have links within Planning Departments... Developers would contact them' (Food Retailer).

Experienced international SD analysts tended to reflect on their knowledge and transfer lessons learned from other countries to new contexts - a process referred to as 'hybridisation' both within the management and economic geography literature (DURAND and WRIGLEY, 2009; GAMBLE, 2010). In this case, it constituted the capability of fusing a business strategy role with a store location and development one, serving to underline the added-value such analysts can offer in assessing appropriate market entry strategy-making. 
Utilising in-house SD planning expertise tended to result in richer engagement and understanding of strategic opportunities within the region than would otherwise be realised by relying exclusively on an external property agent (cf. SHACKLETON, 1998 from a domestic perspective). While these organisations often undertake some elementary location research, their prime motive remains the profitable leasing of retail property. As one site research analyst frankly confirmed:

'They'll introduce you to vacant properties that they have available. They won't necessarily advise you on how to enter the Chinese retail market' (Location Planning Consultancy).

The lack of independence in the provision of strategic advice can be problematic but is still often a characteristic of the process - especially in the case of clothing retailers that often lack a well-resourced SD function. This may be due to the high cost of operating a specialist SD team (cf. WOOD and REYNOLDS, 2011a) but also the relatively lower level of sunk costs incurred by clothing retailers compared to food and general merchandise retailers, given their typically smaller format stores and rented (rather than owned) units. Furthermore, in the case of luxury goods retailers, the choice-set of potential store locations within first-tier cities tends to be restricted to well-known districts and prestigious shopping streets frequented by an affluent target customer base, thereby reducing the range of potential locations that need to be screened (cf. MOORE et al., 2010).

\section{Market Entry}

At the market entry stage, SD analysts were conscious that it was particularly important that the first store openings - when the retailer is effectively unknown in the host region - should provide the basis for a robust presence. Early store openings tend to receive a 
disproportionate degree of press and customer attention, essentially setting the tone for the new retail brand. As a result, this might place an emphasis on developing the first stores in prime pitches within the main cities. As one non-food retail location planner reflected - on his early store developments in a developed European country characterised by an 'arm's length' business environment - exploiting only top quality sites at market entry was essential, though a more pragmatic approach to network planning could subsequently emerge with the success of any venture:

'we are in our infancy and we need to make sure that each store we open now, going forward, is absolutely right for us, because, if we get it wrong now, then...the [country] is not going to flourish. So it's a very critical time. Maybe when we've got 50 stores... we may give less emphasis to having the absolute perfect site for the long run' (Non-Food Retailer).

Having fully appraised the market and forecast the ROI on specific development opportunities, the SD department - often in combination with business development, property and/or strategy functions - typically presented the business case to Board level management for final approval. This strategic plan normally included a detailed initial network plan for the country or region and eventually budgetary sales forecasts for initial store openings to facilitate the resourcing of the units and merchandise planning. While this might often in practice constitute a 'rubber stamping' exercise, given the likely involvement of members of senior management throughout the appraisal process, we found that the final decision regarding market entry was sometimes more nuanced in practice. The referral process to senior management could result in a moderating effect that would set market potential against wider political and economic risks. As one food retailer reflected, in the context of proposed entry to a newly industrialising and evidently 'particularistic' Asian country, a potentially lucrative opportunity that was some way along in the evaluation process was rejected at the final stage for fear of politically driven regulatory change within the proposed host region: 
'There's lot of...enough money going in there - World Bank, you know - so we thought, this could be really good for us... I think when certain directors went and had a look around, they weren't quite as keen, but they were coming at it from... a political viewpoint, in that the Government weren't always open to letting foreign companies come in and build lots of stores. You know, they wanted to control a lot of the development, which the Board felt would restrict our opening programs and make it very difficult... to build any scale' (Food Retailer).

\section{Post Market Entry: Initial Assessment of Entry and Establishing Practices \&}

\section{Routines}

Many models of international retail market expansion appear to neglect the period immediately after market entry and the important need to shore up market position. In contrast, our data reminds us that the process of territorial embeddedness provides for a continuing (re)assessment of regional performance and sustained customer orientation to inform strategic adjustment. This allows managers to share post entry learning within and between retail subsidiaries.

Highly developed SD teams were observed to liaise with marketing departments to understand customer profiles and attitudes to stores. Tracking customer feedback allows retailers to establish how store image has been interpreted which can lead to further format (re-)design or amendment, alteration in the mix of future locations, or indeed shifts in merchandising and pricing policy. Inter-departmental information exchange of this kind was potentially very important in refining the regional embedding process. As one food retailer reflected, when commenting on a small acquisition within one European country located in the Mediterranean and dominated by a 'statist' and 'particularistic' business environment, insight was achieved through intra-firm crossworking between SD and marketing teams: 
'when we went into [Country A], for instance, with [Retailer A], they had I think five stores, so you know, five stores in a country that big isn't a great deal, so you want to learn as much as you can about those stores... You're trying to get... customer exit surveys done soon after opening to understand where people are travelling from.... You don't want to open 100 stores before you understand whether they're going to work' (Food Retailer).

These insights improved understanding of the factors driving store performance - and critically - what was impairing sales levels at particular locations.

Post entry appraisal can identify under-performing regions within the catchment(s) but can also provide a deeper understanding of the factors underpinning store performance with important lessons for subsequent forecasting. As one senior SD planning consultant to several international retailers noted:

'You can still learn some pretty interesting [things], even if they're only sort of two-dimensional, rules about whether there appears to be, even from that very small base, some basic relationships...between sales and store area, between size of market and sales performance, perhaps, depending on the type of retailer you are, between market positioning of the venue and performance' (Location Planning Consultancy).

As a consequence of this initial analysis, strategic plans focused on embedding the store estate within the specific region were commonly revisited.

\section{Post Market Entry: Second Wave Expansion}

Following assessment of the success (or otherwise) of the initial market entry, a process of establishing routines and practices for managing ongoing portfolio management and the strategic organisation of second wave expansion were duties often allocated to SD analysts. Once the ideal network plan had been revised, in the light of the performance of newly opened units, a consensus commonly emerged over the process of site identification, appraisal and reporting, with responsibility for forecast sales numbers 
residing in the SD team - while a property team typically identified sites as close to the agreed network plan as possible. Such an arrangement broadly mirrored the domestic structure, thereby allowing the managers of the new business some degree of autonomy from the parent firm.

In fostering the linkage between parent company and the international subsidiary, there is a need for agreement regarding the network plan and the strategy for its realisation. An executive from one non-food retailer that had recently entered an 'arm's length' business environment with a retail market characterised by limited store development opportunities suggested it was forced to pursue a dual strategy of site identification: short-term "pragmatism" and the "ideal" for the long-term:

'So there's two types of sites we look for. One is a short-term opportunity, for example, where there's a vacant unit that's become available and we feel that it meets our requirements, and we can go in there... with a view to developing our notoriety in the local area... [while we] also look for the perfect site' (Non-Food Retailer).

Such is the need for more integrated strategic planning and communication that our interviewees ${ }^{\mathrm{vi}}$ were quick to suggest the importance of embedding permanent SD analysts, along with a property team, within a region. In the process, contact with local experts allowed the identification of additional development opportunities that would likely be missed if attempting to administer SD from-a-distance. More broadly this permitted closer assessment of the nature of the institutional forces that are powerful shapers of internationalisation dynamics. As one retailer reflected in the context of what COE and WRIGLEY (2007) regard as regional 'second mover' competitive and regulatory responses to initial TNC entry: 
'whether you're going into a new country or you're in an established country, your strategy still needs to evolve and change as the market changes' (Food Retailer, our emphasis).

And as one SD manager reflected on his time managing regional expansion in a 'particularistic' Asian country, a rich understanding of the market and its regulatory change gained from analysts' spatial proximity to the region could allow creative opportunities for store expansion to arise:

'[We identified] a loophole in the planning law that meant that...the equivalent of local plans had all lapsed, so there were certain areas or towns where there was no planning law governing what could be developed. So legally...we looked at every single town where the law had lapsed, where there wasn't another overriding law, and said, suddenly, this plot of land which we couldn't develop before is now developable under the law' (Food Retailer).

This rapid response to regulatory change was possible as the retailer had SD analysts and property development executives working within the host country, who could identify and quickly respond to opportunities.

\section{Intra-Firm Learning between Retail TNC Subsidiaries}

Once a long-term commitment to expansion within a country was made, larger retailers sometimes sought to develop a SD team of indigenous analysts to complement or replace any expatriate specialist(s) from the domestic market. While there are clear cost advantages to utilising local talent, there was also a prevailing view that such recruitment also provided the necessary more intuitive understanding of local cultures of consumption. As one established retailer suggested:

'my view is you have an expat initially... and then you try and recruit locally... because they understand their local culture and they understand the country better than certainly we could' (Food Retailer). 
In the longer term, for those retailers with extensive international retail operations, there may be the potential to establish a form of 'best practice' between international ventures. This is a good illustration of what LOWE and WRIGLEY (2010, pp. 382-3) mean when they refer to 'the 'continuously morphing' retail TNC [that is] reciprocally transformed by its experience of operating across a range of cultural, institutional and regulatory environments'. Such interconnectedness permits the realisation of 'splicing' - 'the creation of novel capabilities attuned to the new markets via a 'recombination' of the retail TNC's existing competencies drawn from other parts of its operations - both from its home market and from its other international subsidiaries' (WRIGLEY and LOWE, 2010, pp. 20). One multi-national retailer had an especially well-developed international SD function that allowed such extensive knowledge sharing:

\begin{abstract}
'we have site research teams in every country, almost, in which we're located... They all report in to a member of the local management team, normally the Chief Executive in that country, but they would have a dotted line in to [the International SD Manager whose]...role is about ensuring best practice and consistency across the world in terms of how we approach site research' (Food \& General Merchandise Retailer).
\end{abstract}

On one level, this tacit knowledge can be partially codified in standardised training manuals though, in some instances, it is known that such knowledge transfer can more usefully take place through face-to-face interaction and forms of training (see AMIN and COHENDET, 2004; FAULCONBRIDGE et al., 2012). Within one multi-national retailer the search for consistency in developing capability between host markets was aided by training events organised for SD managers across different international operations, allowing them to learn from each other in gaining a better understanding of the drivers of store performance across different contexts:

'It was a sort of forecast simulation... so they actually learnt how to forecast in those countries, and thought about what was the same, what was different...[It 
was about thinking more widely] when you don't know the market and you don't have those tools, how do you approach it? And just trying to get them to think about broader techniques, as opposed to being in the thick of it' (Food \& General Merchandise Retailer).

This respondent also suggested that it was more effective to get the analysts from similar regions together as they encountered similar difficulties concerning a lack of data but also related consumer cultures: 'So actually, the UK doesn't have to be the source of... all knowledge'.

Intra-firm learning to facilitate appropriately embedded store development was also identified in instances when SD departments from other international subsidiaries of the retail TNC were requested to resolve perceived weaknesses in international expansion strategy and execution. As one analyst from a non-food retailer with a significant international presence commented, intra-firm co-operation across European international boundaries can lead to significant up-skilling in SD capabilities:

'we're sharing knowledge with them and they're sharing it with us... we're providing a kind of a training academy, for want of a better term, [for them to become]...self-supporting, and that's [our] kind of a vision for international expansion' (Non-Food Retailer).

\section{CONCLUSIONS}

Successful international retail expansion requires retail TNCs to achieve territorial embeddedness within their host market, that is to say: a presence that is tailored to its institutional, cultural, economic, legal and competitive characteristics. While researchers across the social sciences have widely discussed this process in theory, an appreciation of its achievement in practice is largely under-developed. This paper has sought an appreciation of the ways in which selected dimensions of territorial embeddedness are practically realised from the perspective of the SD analysts and 
managers who are responsible for providing a retail business with strategic advice relating to appropriate international market entry, regional expansion and its subsequent management.

It is clear that the practical realisation of territorial embeddedness takes place within the decision-making context of the retail firm which is, itself, a part of wider intra- and inter- firm networks as it responds to (and seeks to influence) its external environment (YEUNG, 2005). The realisation of embeddedness is therefore presented as a process taking place at a variety of spatial scales, as the operator seeks store and distribution networks tailored to the local catchment, region and wider country while also leveraging the efficient operating practices and knowledge networks rooted within the wider retail TNC organisational structure (cf. COE et al., 2011). Given the heterogeneous nature of the cultural, regulatory and institutional characteristics of the regions encountered, the nature of this balance varies across space (cf. FAULCONBRIDGE, 2008). We have therefore observed 'emerging practices' in the realisation of retail embeddedness. This is not to claim that there is some kind of universal model or approach to realising strategic fit within a host region, but underlines the varied experiences that retailers commonly have as they seek to interpret and respond to new geographies.

In particular, the degree of market research and analysis conducted by retailers appeared to relate closely to the level of committed sunk cost related to the market entry. Consequently, large format food retailers were seen to expend relatively greater resources on interpreting host region(s) in greater depth, often via resource intensive multi-disciplinary assessment visits, compared to clothing operators for example. In addition, the nature of the business environment entered affected the extent of analysis undertaken, with 'particularistic' markets especially related to the use of joint ventures 
given their unfamiliar and unpredictable geographies from the perspective of western retail TNCs.

This study has also emphasised the degree to which the research to support appropriately embedded store portfolios relies not only on SD expertise but also on intra-firm networks to provide knowledge sharing and essential learning. In the initial phases of market assessment, SD analysts are well placed to conduct preliminary deskbased reviews of the potential of host markets given their familiarity with dealing with incomplete data. However, more tangible contributions to achieving a close understanding of market dynamics can only come from that physical presence within the market, combined with extensive catchment area examination, competitor analysis and store audits. Analysts' physical presence within a country allows the development of a closer understanding of local cultures of consumption (JACKSON, 2004) and more effective insights into the implications for suitable forms of store development and their locations across the competitive landscape. A physical analyst presence also provides a means for SD executives to work more closely alongside related departments such as property teams, where they may be able to detect and respond more quickly to market opportunities or regulatory changes.

Critically, once established following market entry, territorial embeddedness within a host region requires effective monitoring, with SD departments working in close step with property and marketing functions, as well as other stakeholders such as JV partners, as the store portfolio evolves. This is especially important given the likely 'second mover' responses of indigenous retailers and regulators (COE and WRIGLEY, 2007) as well as the probable 'enhanced imitation' of an entrant's competencies (cf. LOWE and WRIGLEY, 2010). As such a continued learning cycle is critical: Ongoing monitoring, 
analysis and assessment of the performance of the fledgling store portfolio, especially from initial store openings, generate important lessons. These stem both from the tracking of customer feedback to gauge the appropriateness of the existing proposition as well as from the development of more sophisticated forecasting models to inform future regional development planning.

For retailers managing international networks across continents and regions, there is considerable scope for organisational learning to enhance the capability for effective embeddedness. Successful store development, in part, rests on the ability to adapt the portfolio of retail formats to different environments and blend knowledge from multiple locations (CURRAH and WRIGLEY, 2004) - a trait the sector shares with other internationalising business services (FAULCONBRIDGE, 2006; 2007). Our interviews have uncovered the extent to which intra-firm learning relating to market understanding, adaptation and forecasting can cut across the boundaries of subsidiary retail firms, thereby reinforcing the power of the retail TNC.

Of course, while we argue that SD teams are extremely important in the process of achieving territorial embeddedness within retail international retail expansion, we must not diminish the contribution of a range of other departments and actors that play their role in the formation and execution of retail strategy. Equally, there were aspects of the process of realising territorial embeddedness that were not a focus of SD departments and therefore were not explored in depth within our empirical analysis - yet remain critical to success. As such our study has not taken sufficient account of the role of operations and business development teams in the establishment of logistics, supply chain and sourcing networks. On the other hand, our interviews have emphasised certain aspects of the territorial embedding process, namely the extent to which location 
planners can work closely with property teams to secure relevant sites; with space planners to determine the internal arrangement of the proposed store units and with marketing departments to understand the nature and demands of the target customer at both pre- and post-market entry stages. This reinforces the findings of DAWSON (2007, pp. 389) who emphasised the need to 'incorporate internationalisation processes' across the retail business. An holistic approach to retail TNC expansion, with store and locational analysis functions playing a more appropriately integrated role in relation to other parts of the business, appears central to achieving retail presence and performance more attuned to the demands of culturally distant or institutionally nuanced destination regions.

\section{Acknowledgements}

This work is supported by The Nuffield Foundation (Grant No: SGS/36175). We would also like to thank the Society for Location Analysis for their support of this project and for helping us in gaining access to numerous location planning departments of retailers. We appreciate the helpful feedback both from the editor and the referees on earlier drafts of the manuscript. 


\section{FIGURES}

Figure 1: Dimensions of the territorial embeddedness of retail TNCs

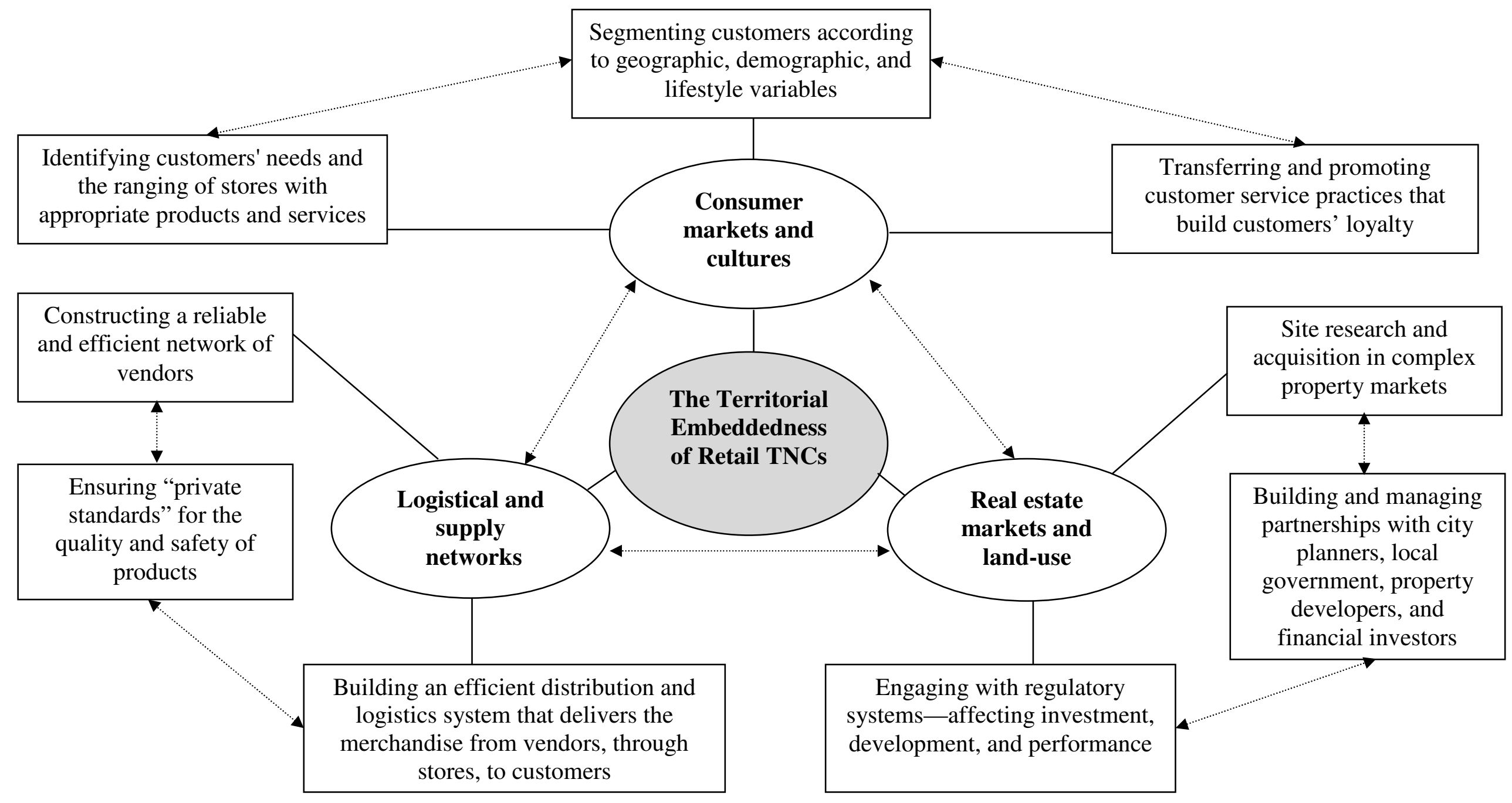

Source: Amended from Tacconelli and Wrigley (2009) 


\section{TABLES}

Table 1: A generic hierarchy of analysis and decision-making in portfolio expansion at a retailer with an established store development planning department

\begin{tabular}{|l|l|l|}
\hline Procedure & Details & Actors \\
\hline $\begin{array}{l}\text { Store strategy } \\
\text { development }\end{array}$ & $\begin{array}{l}\text { Produce plan of optimum geography of } \\
\text { store estate across space }\end{array}$ & SD department \\
\hline $\begin{array}{l}\text { Search for } \\
\text { store/expansion/ } \\
\text { replacement sites }\end{array}$ & $\begin{array}{l}\text { Identify potential locations for portfolio } \\
\text { expansion }\end{array}$ & Property department \\
\hline Appraisal of sites & $\begin{array}{l}\text { Forecast return on investment of site } \\
\text { Provide recommendation regarding } \\
\text { progression (or not) }\end{array}$ & SD department \\
\hline Decision making & $\begin{array}{l}\text { Review sales forecast, likely return on } \\
\text { investment and SD's recommendation } \\
\text { Place in context of wider strategic } \\
\text { thinking } \\
\text { Act on decision (site purchase, rental, } \\
\text { extension, acquisition, closure, re-fascia } \\
\text { or rejection) }\end{array}$ & $\begin{array}{l}\text { Senior management of } \\
\text { retailer } \\
\text { SD department } \\
\text { Property department } \\
\text { Finance department }\end{array}$ \\
\hline Store opening preparation & $\begin{array}{l}\text { Analyse and plan for local marketing } \\
\text { Identify marketing strategy and spatial } \\
\text { extent of marketing coverage } \\
\text { Identify optimum store layout and ranging } \\
\text { for catchment }\end{array}$ & $\begin{array}{l}\text { SD department } \\
\text { Marketing department } \\
\text { Space and range planning } \\
\text { department }\end{array}$ \\
\hline Post opening assessment & $\begin{array}{l}\text { Analyse trade distribution versus forecast } \\
\text { Conduct customer research in-store to } \\
\text { identify any operational and/or } \\
\text { product/marketing related issues } \\
\text { Identify solutions and learnings from } \\
\text { analysis and implement }\end{array}$ & $\begin{array}{l}\text { SD department } \\
\text { Property department } \\
\text { Marketing department } \\
\text { Store operations } \\
\text { department } \\
\text { Space and range planning } \\
\text { department }\end{array}$ \\
\hline
\end{tabular}

Source: Current study 
Table 2: Interview respondents by retail sector

\begin{tabular}{|l|l|l|}
\hline Date of interview & Job title of respondent & Sector \\
\hline November 2009 & Location Planning Manager & Food Retailing \\
\hline November 2009 & Analyst & Department Store Retailing \\
\hline November 2009 & Analyst & Food Retailing \\
\hline November 2009 & Customer Analysis Manager & Department Store Retailing \\
\hline November 2009 & Location Planning Analyst & DIY Retailing \\
\hline November 2009 & Commercial Information Manager & Electrical Retailing \\
\hline December 2009 & Director of Store Development & Non-food Retailing \\
\hline December 2009 & Location Planning Manager & Food Retailing \\
\hline December 2009 & Head of Retailing & Charity Retailing \\
\hline December 2009 & Location Planning Consultant & Electrical Retailing \\
\hline December 2009 & Head of Site Location Services & Location Planning Consultancy \\
\hline January 2010 & Director & Location Planning Consultancy \\
\hline January 2010 & Head of International Development & Location Planning Consultancy \\
\hline January 2010 & Head of Retail Research \& Consultancy & Retail Property Firm \\
\hline January 2010 & Location Planning Manager & Electrical Retailing \\
\hline January 2010 & Director of Retail Location & Location Planning Consultancy \\
\hline January 2010 & Real Estate Market Research Manager & Discount Retailing \\
\hline January 2010 & Store Forecasting \& Development Manager & General Merchandiser \\
\hline February 2010 & Manager of Distribution Strategy & Retail Banking \\
\hline February 2010 & Retail Location Analysis Manager & Food Retailing \\
\hline February 2010 & Country Manager & Clothing Retailing \\
\hline March 2010 & Director of Location Planning & Food Retailing \\
\hline March 2010 & Property \& Development Manager & Sports Retailing \\
\hline March 2010 & Property \& Development Director & Opticians \\
\hline April 2010 & $\begin{array}{l}\text { Focus Group with 10 location analysts from different retailers/location planning } \\
\text { consultancies: }\end{array}$ & \\
\hline & $\bullet \quad$ Food Retailing (2 Analysts); & \\
\hline April 2011 & International Marketing Manager & \\
\hline & & \\
\hline & & \\
\hline & & \\
\hline & Food Retailing (5 Analysts); & Food Retailing \\
\hline & & \\
\hline
\end{tabular}

NB: Interviews listed here include those that were audio recorded and fully transcribed. A number of others were conducted with executives who declined for our conversations to be recorded. In these instances, research notes were made immediately following the exchange and consequently informed the study and its subsequent findings. 
Table 3: A generic typology of the role of store development planning departments in international market retail entry and expansion

\begin{tabular}{|c|c|}
\hline $\begin{array}{l}\text { Stage of international } \\
\text { development }\end{array}$ & Store development planning activity \\
\hline $\begin{array}{l}\text { Pre-market entry: } \\
\text { (a) Country screening }\end{array}$ & 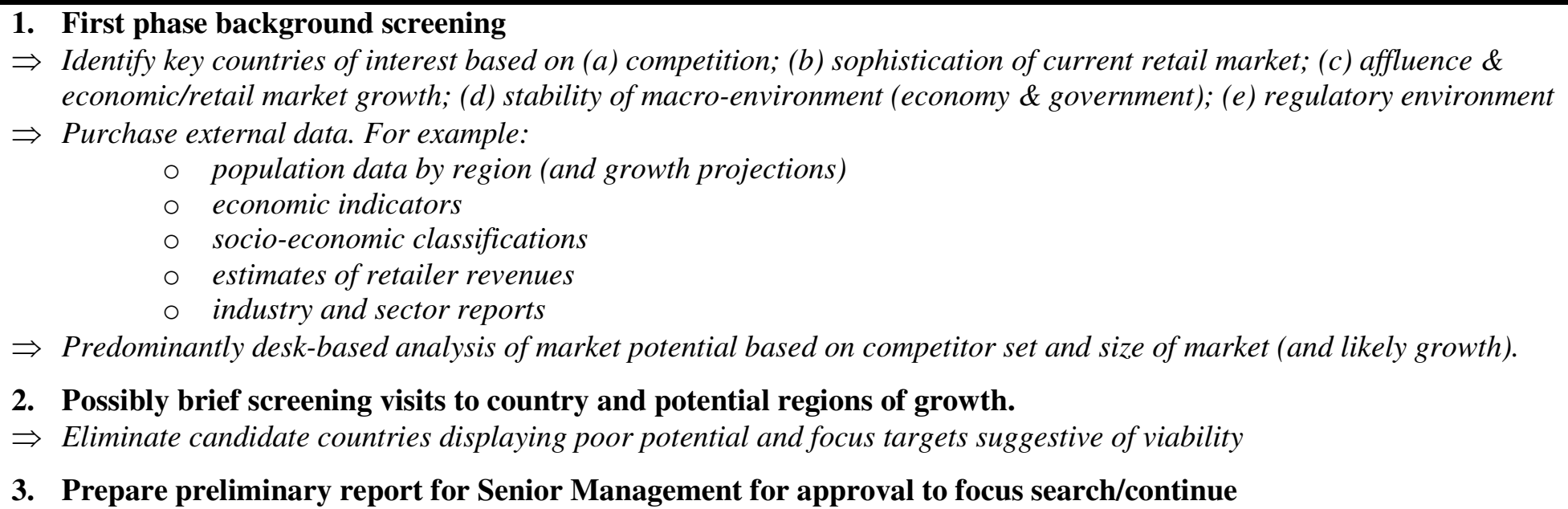 \\
\hline $\begin{array}{l}\text { Pre-market entry: } \\
\text { (b) Entry method analysis }\end{array}$ & $\begin{array}{l}\text { 1. In depth background analysis. } \\
\Rightarrow \text { Increase data concerning country; consumers' competitors and regions under consideration. } \\
\Rightarrow \text { Consider appropriateness of current store formats and proposition for country. } \\
\Rightarrow \text { Consider partnership with local data provider within host country. } \\
\Rightarrow \text { Visit country and specific regions. Potentially undertake extensive periods of fieldwork embedded in localities under } \\
\text { consideration. } \\
\Rightarrow \text { Conduct customer research concerning shopping habits, demands and opinions. } \\
\Rightarrow \text { Analyse performance and formats of incumbent retailers across a variety of locations to gain appreciation of nature of the } \\
\text { competition and how they trade. } \\
\text { 2. Examine potential acquisition targets' portfolios or "partners" for international expansion. } \\
\Rightarrow \text { Conduct indicative initial sales forecasts on likely yields from targets' existing stores. } \\
\Rightarrow \text { Analyse how retailer could "add value" to targets' offer and stores. } \\
\Rightarrow \text { This feeds into cash return on investment appraisals that indicate ceilings on potential payment and ultimately } \\
\text { affordability. } \\
\text { 3. Identify catchments and opportunities for organic growth subsequent to market entry: an early network plan for } \\
\text { the country. } \\
\Rightarrow \text { Using customer data and embedded knowledge from fieldwork, reach an opinion regarding format "type" (e.g. } \\
\text { "standard" format versus "tailored" format for country) }\end{array}$ \\
\hline
\end{tabular}




\begin{tabular}{|c|c|}
\hline & $\begin{array}{l}\Rightarrow \text { Identify region(s) for initial opening } \\
\Rightarrow \text { Conduct early sales forecasts - possibly for a variety of formats } \\
\Rightarrow \text { This feeds into cash return on investment appraisals that indicate ceilings on potential payment and ultimately } \\
\text { affordability. } \\
\text { 4. Recommend to Senior Management an entry strategy } \underline{\mathbf{O R} \text { rejection of opportunity }}\end{array}$ \\
\hline Market entry & $\begin{array}{l}\text { 1. Budgetary sales forecasts } \\
\Rightarrow \text { Extensive site visits and construction of elementary models. } \\
\Rightarrow \text { Produce final sales forecasts for either acquisition or first wave of organic openings. } \\
\Rightarrow \text { Suggest opportunities for local marketing of store conversion from competitor or organic opening. }\end{array}$ \\
\hline $\begin{array}{l}\text { Post market entry: } \\
\text { (a) Initial assessment of } \\
\text { entry }\end{array}$ & $\begin{array}{l}\text { 1. Track performance of initial stores. } \\
\Rightarrow \text { Examine and explain over/under-performance. } \\
\Rightarrow \text { Monitor customer feedback along with Marketing Department concerning experience of stores. } \\
\Rightarrow \text { Use customer data to understand catchments of stores and profile of customers. } \\
\Rightarrow \text { Identify anomalies from forecast performance. Determine causality. } \\
\Rightarrow \text { Revise "ideal" spatial strategy (network plan) for future growth to facilitate (a) identification of new acquisition target } \\
\text { and/or }(b) \text { organic growth opportunities; }(\text { c) the extension/replacement of current units } \\
\text { 2. Recommend to Senior Management plans for strategic growth/retrenchment and/or amendment of current units }\end{array}$ \\
\hline $\begin{array}{l}\text { Post market entry: } \\
\text { (b) } 2^{\text {nd }} \text { wave expansion \& } \\
\text { establishing practices \& } \\
\text { routines }\end{array}$ & $\begin{array}{l}\text { 1. Establish "practices \& routines" in forecasting, develop relationships with Marketing, Operations and Property } \\
\text { Departments } \\
\Rightarrow \text { Develop store development planning team - recruit local specialists and train } \\
\text { 2. Appraise store development opportunities as they occur } \\
\Rightarrow \text { Conduct sales forecasts for new stores: organic developments and/or acquisitions of units as they are brought forward } \\
\Rightarrow \text { Conduct sales forecasts for extensions/refits/replacements of units as they are brought forward. } \\
\Rightarrow \text { Refine and develop sales forecasting models with the benefit of greater data from current stores. } \\
\text { 3. Conduct ad-hoc research concerning individual stores if issues arise } \\
\text { 4. Devise strategies to collect customer data and feedback } \\
\Rightarrow \text { Devise strategy to collect customer feedback across the portfolio } \\
\Rightarrow \text { Consider development of loyalty program to provide continual feedback to retailer. } \\
\text { 5. Consider succession planning of store development planning team if expatriate. } \\
\Rightarrow \text { Develop and train local expertise }\end{array}$ \\
\hline
\end{tabular}

Source: Current study 


\section{REFERENCES}

ALEXANDER N. and DOHERTY A. M. (2009) International Retailing. Oxford, UK: Oxford University Press.

ALEXANDER N., RHODES M. and MYERS H. (2007) International market selection: measuring actions instead of intentions, Journal of Services Marketing 2, 424-34.

AOYAMA Y. (2007) Oligopoly and the structural paradox of retail TNCs: an assessment of Carrefour and Wal-Mart in Japan, Journal of Economic Geography 7, 471-90.

AMIN A. and COHENDET P. (2004) Architectures of Knowledge. Firms, Capabilities, and Communities. Oxford, UK: Oxford University Press.

BATHELT H. and GLÜCKLER J. (2003) Toward a relational economic geography, Journal of Economic Geography 3, 117-144.

BENITO G. R. G. (2005) Divestment and international business strategy, Journal of Economic Geography 5, 235-51.

BIANCHI C. (2009) Retail internationalisation from emerging markets: case study evidence from Chile, International Marketing Review 26, 221-43.

BIANCHI C. C. and OSTALE E. (2006) Lessons learned from unsuccessful internationalisation attempts: Examples of multinational retailers in Chile, Journal of Business Research 59, 140-7.

BIRKIN M., CLARKE G. and CLARKE M. (2002) Retail Geography \& Intelligent Network Planning. Chichester, West Sussex, UK: John Wiley \& Sons.

BOSCHMA R. (2005) Proximity and innovation: a critical assessment, Regional Studies 39, 61 - 74.

BRYMAN A. and BELL E. (2003) Business Research Methods. Oxford, UK: Oxford University Press.

BURT S. and MAVROMMATIS A. (2006) The international transfer of store brand image, International Review of Retail, Distribution \& Consumer Research 16, 395-413.

CHANEY I. and GAMBLE J. (2008) Retail store ownership influences on Chinese consumers, International Business Review 17, 170-83.

CHRISTOPHERSON S. (2007) Barriers to 'US style' lean retailing: the case of Wal-Mart's failure in Germany, Journal of Economic Geography 7, 451-69.

CLARK G. (1998) Stylized facts and close dialogue: methodology in economic geography, Annals of Association of American Geographers 88, 73-87. 
CLARK G. and WRIGLEY N. (1997) Exit, the firm and sunk costs: reconceptualizing the corporate geography of disinvestment and plant closure, Progress in Human Geography 21, 338-58.

COE N. (2004) The internationalisation/globalisation of retailing: towards an economic-geographical research agenda, Environment and Planning A 36, 1571-94.

COE N. and HESS M. (2005) The internationalization of retailing: implications for supply network restructuring in East Asia and Eastern Europe, Journal of Economic Geography 5, 449-73.

COE N. M., JOHNS J. and WARD K. (2011) Variegated global expansion: Internationalization strategies in the temporary staffing industry, Geoforum 42, 61-70.

COE N. and LEE Y.-S. (2006) The strategic localization of transnational retailers: the case of Samsung-Tesco in South Korea, Economic Geography 82, 61-88.

COE N. and WRIGLEY N. (2007) Host economy impacts of transnational retail: the research agenda, Journal of Economic Geography 7, 341-71.

COE N. and WRIGLEY N. eds. (2009) The Globalization of Retailing. Cheltenham, UK: Edward Elgar.

CURRAH A. and WRIGLEY N. (2004) Networks of organizational learning and adaptation in retail TNCs, Global Networks 4, 1-23.

COE N., DICKEN P. and HESS M. (2008) Global production networks: realising the potential, Journal of Economic Geography 8, 271-295.

DAWSON J. A. (2007) Scoping and conceptualising retailer internationalisation, Journal of Economic Geography 7, 373-97.

DICKEN P. (2000) Places and flows: situating international investment. In The Oxford Handbook of Economic Geography, ed. G. L.Clark, M. Feldman, M. Gertler, 275-291, Oxford: Oxford University Press.

DOHERTY A. M. (1999) Explaining international retailers' market entry mode strategy: internalization theory, agency theory and the importance of information asymmetry, The International Review of Retail, Distribution and Consumer Research 9, 379-402.

DONALD B. (2008) Food systems planning and sustainable cities and regions: the role of the firm in sustainable food capitalism, Regional Studies 42, 1251 - 62.

DURAND C. and WRIGLEY N. (2009) Institutional and economic determinants of transnational retailer expansion and performance: a comparative analysis of Wal-Mart and Carrefour, Environment and Planning A 41, 1534-55. 
EL-AMIR A. and BURT S. (2008) Sainsbury's in Egypt: the strange case of Dr Jekyll and Mr Hyde?, International Journal of Retail \& Distribution Management 36, 300-22.

FAULCONBRIDGE J. R. (2006) Stretching tacit knowledge beyond a local fix? Global spaces of learning in advertising professional service firms, Journal of Economic Geography 6, 517-40.

FAULCONBRIDGE J. R. (2007) Exploring the role of professional associations in collective learning in London and New York's advertising and law professional-service-firm clusters, Environment and Planning A 39, 965-84.

FAULCONBRIDGE J. R. (2008) Managing the transnational law firm: A relational analysis of professional systems, embedded actors, and time-space-sensitive governance, Economic Geography 84, 185-210.

FAULCONBRIDGE J. (2010) TNCs as embedded social communities: transdisciplinary perspectives, Critical Perspectives on International Business 6, 273-290.

FAULCONBRIDGE J. R., MUZIO D. and COOK A. (2012) Institutional legacies in TNCs and their management through training academies: the case of transnational law firms in Italy, Global Networks 12, 48-70.

GAMBLE J. (2010) Transferring organizational practices and the dynamics of hybridization: Japanese retail multinationals in China, Journal of Management Studies 47, 705-32.

GERTLER M. S. (2004) Manufacturing Culture: the Institutional Geography of Industrial Practice. Oxford University Press, Oxford.

GLÜCKLER J. (2006) A relational assessment of international market entry in management consulting, Journal of Economic Geography 6, 369-393.

HENSON S. and REARDON T. (2005) Private agri-food standards: Implications for food policy and the agri-food system, Food Policy 30, 241-53.

HESS M. (2004) 'Spatial' relationships? Towards a reconceptualization of embeddedness, Progress in Human Geography 28, 165-86.

HUGHES A. (2012) Corporate ethical trading in an economic downturn: recessionary pressures and refracted responsibilities, Journal of Economic Geography 12, 33-54.

HUMPHREY J. (2007) The supermarket revolution in developing countries: tidal wave or tough competitive struggle?, Journal of Economic Geography 7:433-50. 
HUTCHINSON K., QUINN B., ALEXANDER N. and DOHERTY A. M. (2009) Retailer internationalization: overcoming barriers to expansion, The International Review of Retail, Distribution and Consumer Research 19, 251-72.

IVARSSON I. and ALVSTAM C. G. (2011) Upgrading in global value-chains: a case study of technology-learning among IKEA-suppliers in China and Southeast Asia, Journal of Economic Geography 11, 731-52.

JACKSON P. (2004) Local consumption cultures in a globalizing world, Transactions of the Institute of British Geographers 29, 165-78.

JONES A. (2005) Truly global corporations? Theorizing 'organizational globalization' in advanced business-services, Journal of Economic Geography 5, 177-200.

JONES A. (2008) Beyond embeddedness: economic practices and the invisible dimensions of transnational business activity, Progress in Human Geography 32, 71-88.

JONES A. and MURPHY J. T. (2010) Theorizing practice in economic geography: Foundations, challenges, and possibilities, Progress in Human Geography.

JONSSON A. (2008) A transnational perspective on knowledge sharing: lessons learned from IKEA's entry into Russia, China and Japan, International Review of Retail, Distribution \& Consumer Research 18, 17-44.

LAULAJAINEN R. (1987) Spatial Strategies in Retailing, D. Reidel: Dordrecht, Netherlands.

LOVE J. H., ROPER S. and HEWITT-DUNDAS N. (2010) Service Innovation, embeddedness and business performance: evidence from Northern Ireland, Regional Studies 44, 983 - 1004.

LOWE M. and WRIGLEY N. (2009) Innovation in market entry: Tesco in the USA, International Review of Retail, Distribution \& Consumer Research 19, 331-47.

LOWE M. and WRIGLEY N. (2010) The 'continuously morphing' retail TNC during market entry: interpreting Tesco's expansion into the USA, Economic Geography 86, 381-408.

MOORE C., DOHERTY A. M. and DOYLE S. (2010) Flagship stores as a market entry method: The perspective of luxury fashion retailing, European Journal of Marketing 44, 139-61.

MUTEBI A. M. (2007) Regulatory responses to large-format transnational retail in south-east Asian cities, Urban Studies 44, 357-79.

NORDÅS H. K. (2008) Gatekeepers to consumer markets: the role of retailers in international trade, The International Review of Retail, Distribution and Consumer Research 18, 449-72. 
OKEAHALAM C. and WOOD S. (2009) Financing internationalisation: a case study of an African retail transnational corporation, Journal of Economic Geography 9, 511-37.

PALMER M. (2006) International retail joint venture learning, Service Industries Journal 26, 165-87.

PALMER M., OWENS M. and DE KERVENOAEL R. (2010) Paths of the least resistance: understanding how motives form in international retail joint venturing, The Service Industries Journal 30, 965-89.

PALMER M. \& QUINN B. (2007) The nature of international retail divestment: Insights from Ahold. International Marketing Review 24, 26-45.

PHELPS N. A., MACKINNON D., STONE I. and BRAIDFORD P. (2003) Embedding the multinationals? Institutions and the development of overseas manufacturing affiliates in Wales and North East England, Regional Studies 37, 27 - 40.

PICKLES J. and SMITH A. (2011) Delocalization and persistence in the European clothing industry: the reconfiguration of trade and production networks, Regional Studies 45, 167-85.

POOLE R., CLARKE G. P. and CLARKE D. B. (2002) Grocery retailers and regional monopolies, Regional Studies 36, 643-59.

REARDON T., HENSON S. and BERDEGUE J. 2007. 'Proactive fast-tracking' diffusion of supermarkets in developing countries: implications for market institutions and trade, Journal of Economic Geography 7, 399-431.

REYNOLDS J. and WOOD S. (2010) Location decision-making in retail firms: evolution and challenge, International Journal of Retail \& Distribution Management 38, 828-845.

SHACKLETON R. (1998) Exploring corporate culture and strategy: Sainsbury at home and abroad during the early to mid 1990s, Environment and Planning A 30, 921-40.

SWOBODA B., SCHWARZ S. and HÄLSIG F. (2007) Towards a conceptual model of country market selection: Selection processes of retailers and C\&C wholesalers, International Review of Retail, Distribution \& Consumer Research 17, 253-82.

TACCONELLI W. and WRIGLEY N. (2009) Organizational challenges and strategic responses of retail TNCs in post-WTO-entry China, Economic Geography 85, 49-73.

TOKATLI N. and KIZILGÜN Ö. (2010) Coping with the changing rules of the game in the global textiles and apparel industries: evidence from Turkey and Morocco, Journal of Economic Geography 10, 209-29. 
WHITLEY R. (2001) How and why are international firms different? The consequences of crossborder managerial coordination for firm characteristics and behaviour. In Morgan, G., Kristensen, P.H. and Whitley, R. (eds) The Multinational Firm: Organizing Across Institutional and National Divides, Oxford: Oxford University Press: 27-68.

WOOD S. (2001) Regulatory constrained portfolio restructuring: the US department store industry in the 1990s, Environment and Planning A 33, 1279-1304.

WOOD S. (2002) The limits to portfolio restructuring: lessons from regional consolidation in the US department store industry, Regional Studies 36, 515 - 29.

WOOD S. and REYNOLDS J. (2011a) The intra-firm context of retail expansion planning. Environment and Planning A 43, 2468-2491.

WOOD S. and REYNOLDS J. (2011b) Knowledge management, organisational learning and memory in UK retail network planning, The Service Industries Journal, DOI:10.1080/02642069.2011.614340.

WOOD S. and REYNOLDS J. (2012) Managing communities and managing knowledge: strategic decision making and store network investment within retail multinationals, Journal of Economic Geography 12, 539-565.

WRIGLEY N., COE N. and CURRAH A. (2005) Globalizing retail: conceptualizing the distributionbased transnational corporation TNC., Progress in Human Geography 29, 437-57.

WRIGLEY N. and CURRAH A. (2003) The stresses of retail internationalization: lessons from Royal Ahold's experience in Latin America, International Review of Retail, Distribution \& Consumer Research 13, 221-43.

WRIGLEY N. and LOWE M. (2010) The Globalization of Trade in Retail Services. Report commissioned by the OECD Trade Policy Linkages and Services Division for the OECD Experts Meeting on Distribution Services, Paris 17 November 2010. Accessed at http://www.oecd.org/dataoecd/1/49/46329746.pdf on 12 January 2011.

YEUNG H. W.-C. (2005) The firm as social networks: an organisational perspective, Growth and Change 36, 307-328.

YEUNG H. W.-C. (2009) Transnationalizing entrepreneurship: a critical agenda for economic geography, Progress in Human Geography 33, 210-35. 


\section{ENDNOTES}

i We have used the term 'region' in this paper to denote 'sub-national spaces' rather than spaces at the national scale and larger.

ii An EDLP approach to pricing seeks to provide customers with consistent low prices across its product offer rather than a highly promotional so-called "high-low" pricing strategy where a few highly visible discounted products fuel customer excitement, yet the overall price of a basket of goods are more expensive.

${ }^{\text {iii }}$ We are aware of the static nature of such a three-fold classification of business environments but employ it within this research paper as a means of describing the nature of the host country at the point of entry and/or expansion without compromising the anonymity of the retailers concerned.

iv Variations include "location planning"; "site research" as well as the term "store development" that we employ in this paper.

${ }^{v}$ In some markets, where the nature of entry is constrained (for example, as in India as a result of Foreign Direct Investment controls), identifying a suitable domestic retail partner is a legal prerequisite for investment.

${ }^{\mathrm{vi}}$ In this case, they tended to be disproportionately located within the larger store development units of food and general merchandise retailers. 